\title{
Increasing the operating depth of an autonomous underwater vehicle using an intelligent magnetic field
}

\author{
Ali Jebelli ${ }^{1}$, Arezoo Mahabadi ${ }^{2}$, Hicham Chaoui ${ }^{3}$, Mustapha C. E. Yagoub ${ }^{4}$ \\ ${ }^{1,3}$ Department of Electronics, Carleton University, Ottawa, Canada \\ ${ }^{2}$ School of Engineering Science, Tehran University, Tehran, Iran \\ ${ }^{4}$ School of Electrical Engineering and Computer Science, University of Ottawa, Ottawa, Canada
}

\begin{tabular}{l} 
Article Info \\
\hline Article history: \\
Received Mar 3, 2021 \\
Revised Jul 8, 2021 \\
Accepted Jul 23, 2021 \\
\hline Keywords: \\
Autonomous underwater \\
vehicles \\
Fuzzy logic \\
Magnetic field \\
MATLAB \\
Mini pc \\
Polytetrafluoroethylene \\
SOLIDWORKS
\end{tabular}

\begin{abstract}
Designing and manufacturing a suitable body is one of the most effective factors in increasing the efficiency of autonomous underwater vehicles (AUVs). In fact, increasing the propulsive power of an AUV by reducing the frictional drag on its body and increasing its maneuverability will positively affect key parts of the AUV's hardware and software such as control system, sensors, AUV vision, batteries and thrusters. On the other hand, a suitable body should have features such as lightness, underwater vehicle's balance, high mechanical strength, and enough space for equipment. Therefore, the design and manufacture of the body requires a lot of analysis in terms of body material, aerodynamic calculations, etc., increases the overall cost. This paper aims to reduce the stress in the body of a Polytetrafluoroethylene (PTFE) underwater robot and to increase its operating depth without changing the body's structure by using fuzzy logic to intelligently controlling the magnetic force generated by the repulsion between the coil and the cylindrical magnet, which saves energy, reduces battery consumption, and increases system performance. The results show that the robot performance depth increases by more than $50 \%$ without changing the robot body structure.
\end{abstract}

This is an open access article under the CC BY-SA license.

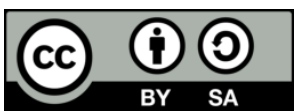

\section{Corresponding Author:}

\section{Ali Jebelli}

Department of Mechanical Engineering

University of Alberta

Edmonton, Canada

Email: jebelli@ualberta.ca

\section{INTRODUCTION}

Due to their increasing use in the marine industry and marine research, autonomous underwater vehicles (AUVs) are of particular importance. The underwater environment poses many challenges for researchers and submarine artisans [1], [2]. As the water depth increases, the pressure, temperature and $\mathrm{pH}$ of the water change, which can cause the vehicle to corrode, break, or even sink [1]-[10]. Therefore, the body of the underwater vehicle must be designed in such a way that in addition to high strength (for proper working depth and operating period), they also have the ability to maneuver properly so that they can cross through existing obstacles without any collision. Autosub6000 despite the high depth rating, it is about 5.5 meters long and the body material and batteries cause the very high weight of this robot, which requires a secondary system such as a boat to change the depth of the robot [11]. Also, the cylindrical and long shape of the system increases the strength of the body, but reduces the maneuverability of the robot, so the robot needs to move in a wide range of motion to cross obstacles. In addition to the importance of body strength at different temperatures and depths, the implementation of tracking and mapping system and robot movement system to 
reduce errors in predicting robot movement in body design is effective and the implementation of these factors is sometimes so complex and difficult which designers abandon one or more of these factors [12].

Moreover, to increase the maneuverability of the system, designers may need to increase the number of trusts and thus the capacity of the system batteries, which increases the weight of the robot and according to the final weight is needed to reduce the density of the body so that in addition to having enough volume for the batteries, sensors and control system, the final weight of the robot does not increase. Because as the weight of the robot increases, more powerful thrusters are needed, and so the system needs more battery. Therefore, another challenge is to choose a light and strong material for the body that does not deform and crack when the depth pressure increases. The UTeM robot has high maneuverability, but its energy source is very limited and does not have the ability to increase depth. This robot has 4 thrusters and a very small body that gives the robot high maneuverability and can easily cross various obstacles, but with increasing depth, the body loses its efficiency and also the limited energy source reduces the operating time of the robot [13]. In addition, designing a robot with multiple thrusters to increase maneuverability and depth change is very usual, but it should be noted that the placement of multiple thrusters should be such that the water flow path does not affect other thrusters. On both sides of the body of the DEMarine robot, metal sheets have been placed so that in addition to the possibility of adding four thrusters to the system, the fragile body of the robot is protected from both sides so that it does not crack and sink when it encounters obstacles. But these metal sheets have limited the robot's movement system and reduced the robot's maneuverability because the robot needs more space to turn [14].

In this paper, the intelligent repulsion force between the coil and magnet is used to reduce the pressure on the vehicle body at different depths, which allows increasing the allowable bearing pressure of the vehicle, enabling it to operate at more depths. The body pressure analysis was simulated in SOLIDWORKS and the magnetic system and fuzzy controller calculations implemented as MATLAB in the vehicle control system, a high-speed mini-PC.

\section{TOOLS AND EQUIPMENT}

Underwater vehicles have many challenges due to their working conditions and type of activity to be able to maneuver properly in carrying out their mission. These challenges can be the effects of underwater pressure on the body, increasing the weight of the system due to the installation of equipment and thrusters [3]-[8].

In this research, we designed a lightweight AUV equipped with two cameras to track the surrounding environment. It can perform $360^{\circ}$ maneuver under water with only two rotating thrusters and a mass shifter that moves horizontally inside its body. To the best authors' knowledge, this is the first of its kind. We also implemented an efficient algorithm to control the AUV operation by varying the angle and speed of the thrusters necessary to reach a given position with minimal energy consumption. It matches in real-time the data received from embedded sensors with the images from two cameras and a sonar system. Each of these boards is capable of processing the information received from the batteries and engines, which considerably reduces the AUV's energy use and significantly increases the operating time of the AUV in water. These boards are connected to a mini computer located in the bottom of the AUV. With a very high processing speed, it simultaneously matches the data received from the sensors, engines, batteries, and cameras with the predefined AUV target path so that the unmanned AUV can choose the best, safest, and shortest route to reach its target [6]-[8]. Figure 1(a) shows plan of robot structure with orthogonal and isometric view and Figure 1(b) [15].

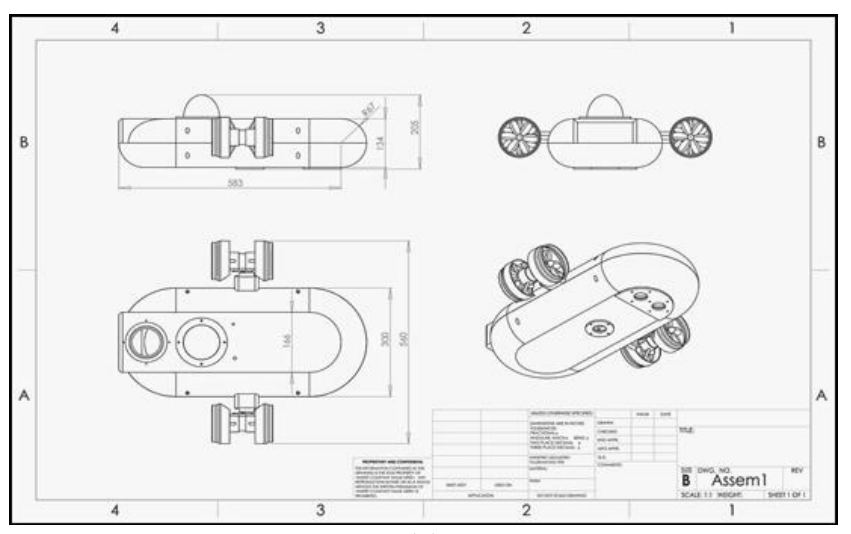

(a)

IAES Int J Rob \& Autom, Vol. 10, No. 3, September 2021: 207 - 223 


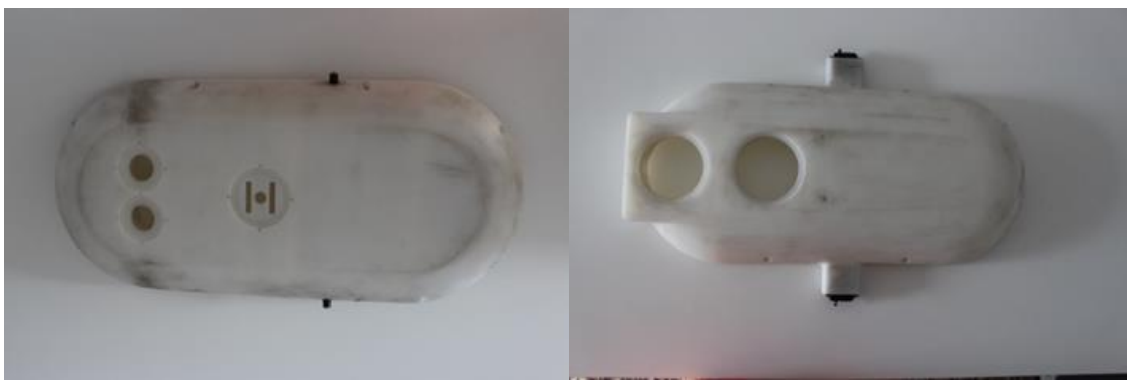

(b)

Figure 1. Designed robot: (a) Isometric scheme of the designed robot, (b) Different views of the designed robot

\subsection{Body material}

The body of the AUV and its components are made of (Polytetrafluoroethylene) PTFE Teflon [7]. Teflon is a polymer with a molecule made of carbon fluorine atoms strongly connected to each other [7]. This material is very strong and highly recommended due to its numerous plastic features. It is widely used in industry and has practical suitable features such as high resistance against chemical factors, high resistance against adherence, and high dielectric features. However, one of its main advantages remains its flexibility. In accordance with the ASTM D790 standard, plastic form and flexibility of Teflon in natural temperature is about $50-650 \mathrm{~N} / \mathrm{mm}^{2}$. Teflon is also one of the best and valuable electrical insulators. It should be also mentioned that Teflon retains this feature in different atmospheric, and temperature conditions as well as at different frequencies [7]. The Pressure sensor used in this AUV is MS5803-14BA, which works with the I2C protocol and has a measurement accuracy and measuring power of up to 14 bars [6], [7].

\section{MAGNETIC RELATIONS}

Let us assume a cylindrical coil coaxial with the z-axis of a cylindrical coordinate system. By dividing the environment into homogeneous parts, the magnetic potential can be calculated by solving the non-homogenous Poisson equation. The governing Poisson equation for calculating the vector magnetic potential is as (1) [9].

$$
\nabla^{2} A=-\mu J
$$

Where $\mu$ is the permeability, $\mathrm{A}$ is the vector potential, and $\mathrm{J}$ the vector current density.

In a symmetrical environment with respect to the $\mathrm{z}$-axis, the potential of each zone is as (2) [4].

$$
A=\sum_{n}\left(a_{n} I_{1}\left(k_{n} r\right)+b_{n} K_{1}\left(k_{n} r\right)-C_{n} L_{1}\left(k_{n} r\right)\right) \sin \left(k_{n} z\right)
$$

Where $\mathrm{I}_{\mathrm{m}}$ and $\mathrm{K}_{\mathrm{m}}$ are the modified Bessel functions of the first and second types, and $\mathrm{L}$ is the modified Struve function. The coefficient $\mathrm{Cn}$ is calculated according to the current density $\mathrm{J}$ and the coefficients $a_{n}$ and $b_{n}$ are calculated based on the boundary conditions.

If the system is assumed homogeneous, the magnetic potential A and the magnetic field are calculated directly. In this paper, the permeability of the magnet is considered equal to that of the air. Any current density in a given volume can be equated with a magnetization [10]. Therefore, a cylindrical magnet can be equated with a thin-walled cylindrical coil, and the magnetic relations can be written based on the equivalent coil as shown in Figure 2.

For a magnet, the polarization of the magnet $\mathrm{P}$ can be equated with the current density $J[16]$.

$\nabla \times P=\mu_{0} J$

If the magnet is a cylindrical magnet, the equivalent current density is calculated as (4) [10].

$$
J=\frac{P \times n}{\mu_{0}}
$$

Where $\mathrm{n}$ is a unit vector perpendicular to the outer surface of the magnet and $\mu_{0}$ is the vacuum magnetic permeability constant.

Increasing the operating depth of an autonomous underwater vehicle using an intelligent ... (Ali Jebelli) 
The force between two coils is calculated by the finite element method. Each coil is divided into a number of current-carrying loops and the force between each loop is obtained by the Maxwell loop relations (relation 5). Finally, the force between the two coils is obtained by summing the elements up [17]. The magnetic force between two coaxial current loops (Maxwell loop) is calculated as (5) and (6).

$$
F=\frac{\mu_{0} I_{1} I_{2} k z_{Q}}{4 \sqrt{R_{1} R_{2}}}\left[\frac{\left(2-k^{2}\right)}{\left(1-k^{2}\right)} E(k)-2 K(k)\right]
$$

With

$$
k^{2}=\frac{4 R_{1} R_{2}}{\left(R_{1}+R_{2}\right)^{2}+z_{Q}^{2}}
$$

Where $R_{1}$ is the radius of the first current loop, $R_{2}$ is the radius of the first current loop, $z_{Q}$ is the distance between the two loops, $I_{1}$ and $I_{2}$ are the current of loops, $E(k)$ and $K(k)$ are elliptic integrals of first and second kind.

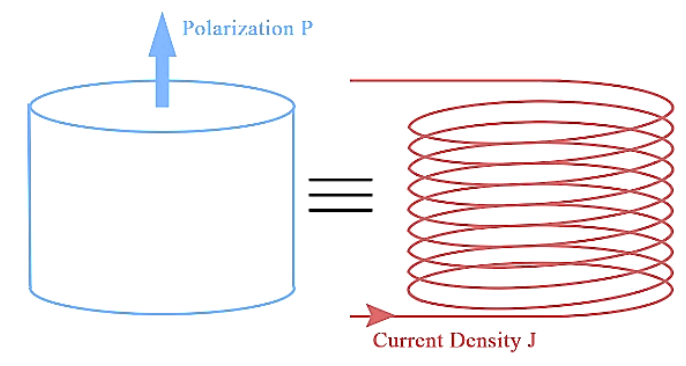

Figure 2. Equivalent cylindrical magnet and thin-walled coil

\section{STRESS}

For each surface element, a symmetric matrix of the stresses applied on it is written, which is called a stress tensor [18].

$$
T=\left[\begin{array}{ccc}
\sigma_{x} & \tau_{x y} & \tau_{x z} \\
\tau_{y x} & \sigma_{y} & \tau_{y z} \\
\tau_{z x} & \tau_{z y} & \sigma_{z}
\end{array}\right]
$$

Where $\sigma$ is the vertical stress and $\tau$ is the shear stress. Stress equations are differential equations with boundary conditions. The vertical stress is obtained by the sum of axial and flexural stress. Table 1 shows the formula for vertical and shear stresses [19], [20].

Table 1. Vertical and shear stresses formula

\begin{tabular}{ccc}
\hline Type of stresses & Formula & Description \\
\hline Shear stress & $\tau=\frac{V}{A}$ & Dividing the shear force by the cross-sectional area \\
Axial stress & $\sigma=\frac{F}{A}$ & Dividing the vertical force by the cross-sectional area \\
\hline
\end{tabular}


According to the beam theory, based on the assumptions of plane sections remaining plane and negligible transverse strain, the strain varies linearly with thickness [19]. When the part under study is isotropic and homogeneous, these equations become linear and are written based on the load applied on the surface [19], [20]. This means that for the loads $P_{1}$ and $P_{2}$ and the scalar coefficients a and $b$ in a specific element, the relation is $(8)$.

$$
T_{1}=f\left(P_{1}\right), T_{2}=f\left(P_{2}\right) \rightarrow f\left(a P_{1}+b P_{2}\right)=a T_{1}+b T_{2}
$$
on (9).

The applied load in this paper is water pressure. The water pressure on the body is obtained based

$$
P=\rho g h
$$

Where $\mathrm{g}$ is the acceleration of gravity (Near Earth's surface, this parameter is approximately $9.81 \mathrm{~m} / \mathrm{s}^{2}$ ); $\mathrm{h}$ is the depth of water and $\rho$ is the density of water $\left(1000 \mathrm{~kg} / \mathrm{m}^{3}\right)$. Therefore, by increasing the water depth by 1 meter, the applied pressure increases by $9.81 * 10^{3} \mathrm{~Pa}$.

The maximum von Mises allowable load on a body made of PTFE is 6.57 MPa [20]. Von Mises stress on the body for a depth of 1 meter under water is shown in Figure 3.

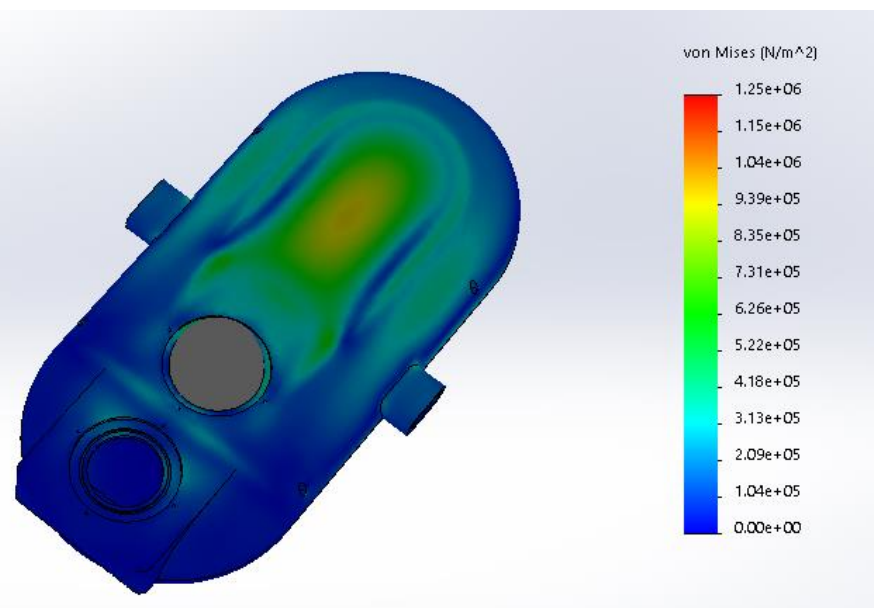

Figure 3. Von Mises stress at a depth of $1 \mathrm{~m}$ underwater

The maximum stress in the vehicle nose is $9.63 * 10^{5} \mathrm{~Pa}$, which is specified as light orange in the image. The maximum stress on the body is the shear stress resulting from the edges being filled in the actual condition.

The thickness of the nose is constant and the pressure on it is uniform. Therefore, the stress relations in this system are linear. Due to the linearity of the stress relations, the maximum allowable depth of the body can be calculated using the fit (10).

$$
h_{\max }=\frac{\sigma_{\max }}{\sigma_{1}}=\frac{6.57 * 10^{6}}{9.63 * 10^{5}}=6.82 \mathrm{~m}
$$

Where $\mathrm{h}_{\max }$ is the maximum allowable depth, $\sigma_{1}$ is the Von Mises stress at a depth of one meter, and $\sigma_{\max }$ is the maximum allowable body stress. For higher safety, the maximum depth of the system has been set to 6.5 meters, see in Figure 4. 


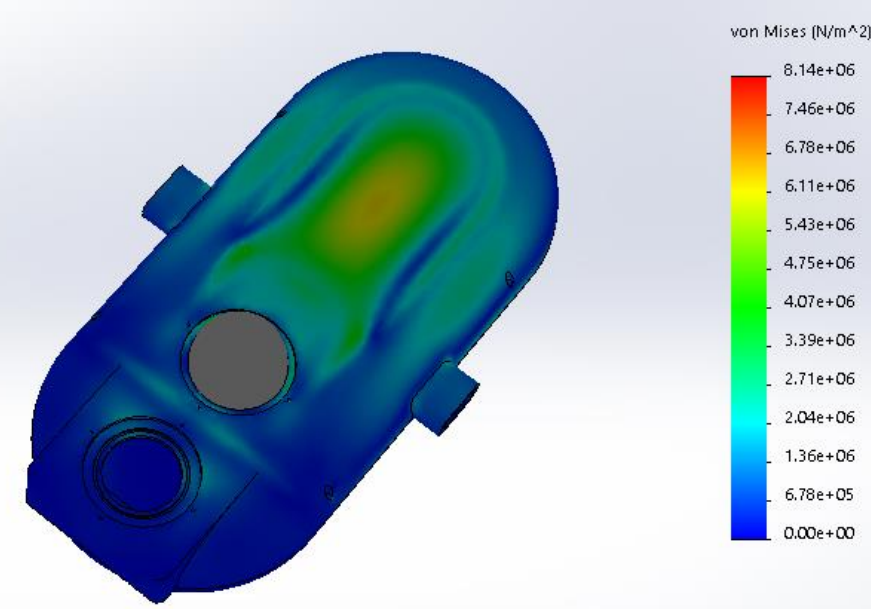

Figure 4. Body stress at a depth of $6.5 \mathrm{~m}$. As can be seen, the body stress has increased 6.5 times relative to the depth of 1 meter

\section{PRESSURE NEUTRALIZATION WITH MAGNET}

Different methods are used to increase the allowable depth of the vehicles. Changes in the physical structure of the AUV such as adding ribs and columns to reduce the pressure level, increasing the thickness and material of the body are among the methods to reduce the body stress and increase its working depth that each has its own advantages and disadvantages. Among the disadvantages of these methods is the change in the physical structure and material of the body, which poses challenges such as increasing the weight of the body, reducing the internal space of the vehicle for the required equipment, changing the size of the vehicle, and the need for complete re-analysis of the body and system dynamics. In this paper, the stress in the body is neutralized by a very small magnetic intelligent system consisting of a coil and a magnet in a low-cost and light-weighted system. Therefore, this small, light, and low-cost system allows increasing the AUV's allowable operating depth significantly without changing the body structure. This magnetic force generated inside the system enters the surface of the nose. According to the depth required by the designed AUV, a neodymium cylindrical magnet with a thickness of $3 \mathrm{~cm}$ and a height of $3 \mathrm{~cm}$ is used. The reason for choosing this small volume of this magnet model is high magnetic strength and the reduced coil volume.

This study is intended to increase the working depth of the body to a depth of 10 meters. Therefore, the maximum pressure entering the body at this depth is equal to $9.81 * 10^{4} \mathrm{~Pa}$. Due to the linearity of the equation, the stress of Von Mises body is ten times greater than the stress at a depth of one meter, see in Figure 5.

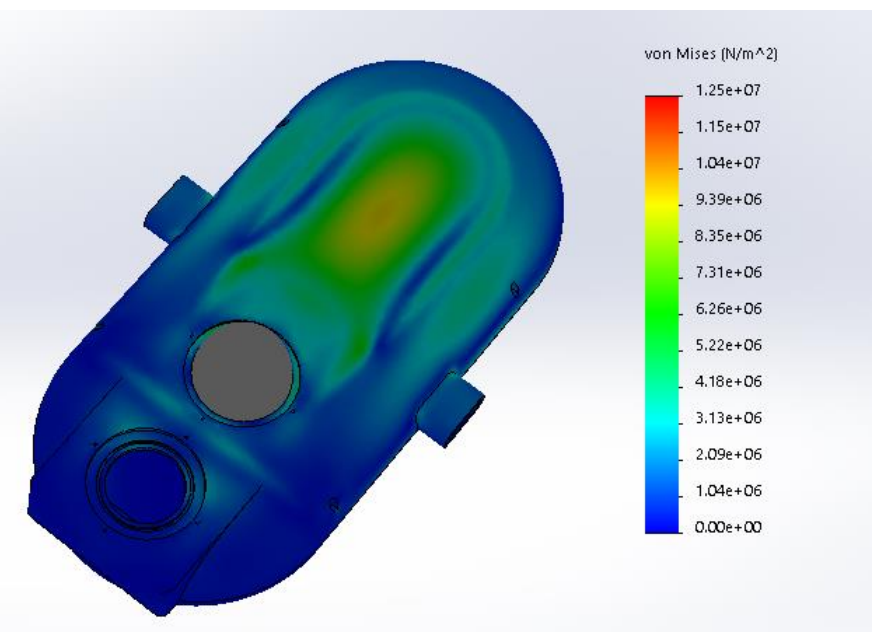

Figure 5. Body stress at a depth of 10 meters $\left(9.81 * 10^{4} \mathrm{~Pa}\right)$ with a maximum stress at the AUV nose of $9.63 * 10^{6} \mathrm{~Pa}$ 
To apply 10 meters of water pressure from inside with the selected magnet, the resulting stress in the body is shown in Figure 6.

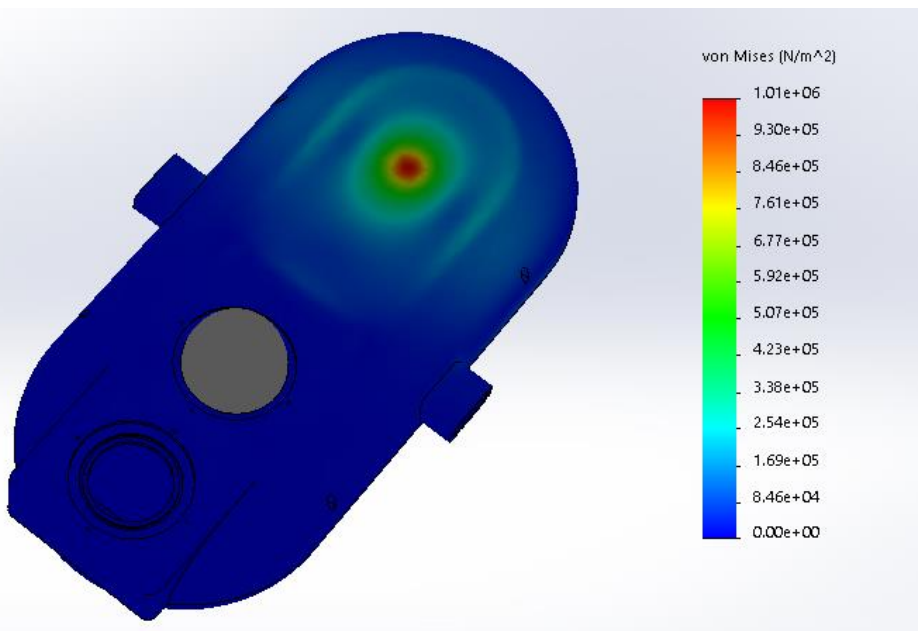

Figure 6. Von Mises stress on the body with an internal pressure of $9.81 * 10^{4} \mathrm{~Pa}$ (equivalent to $69.3 \mathrm{~N}$ ) on a circle with a diameter of $3 \mathrm{~cm}$

According to Figure 6, if the maximum nose stress is applied at a depth of 10 meters within the allowable range of PTFE stress, there should be an internal force of 3.03 times.

The amount of stress that must be neutralized to reach the allowable working depth of 10 meters $=$ $9.63 * 10^{6}-6.57 * 10^{6}=3.06 * 10^{6}$ pa.

$$
\begin{aligned}
& \frac{\sigma_{1}}{\sigma_{2}}=\frac{P_{1}}{P_{2}} \rightarrow \frac{1.01 * 10^{6}}{3.06 * 10^{6}}=\frac{98100 \mathrm{~Pa}}{P_{2}} \\
& \mathrm{P} 2=3.03 * \mathrm{P} 1=3.03 * 98100 \mathrm{pa}
\end{aligned}
$$

Where $\mathrm{P}_{2}$ is external pressure, $\mathrm{P}_{1}$ is internal pressure, $\sigma_{1}$ is external stress and $\sigma_{2}$ is internal stress.

According to Figure 6, the effective surface of the magnet is small, a small part of the nose is red, a small surface has turned green, which means that the radius that the magnetic system affects to reduce stress is small. To increase the radius of impact of the magnet force and reduce the stress caused by water pressure, a very light piece of Teflon is used. The thickness of this piece is $4 \mathrm{~mm}$, the effective surface of which (the area in contact with the body) is equal to the cross section of the magnet, but the effective radius is more. The geometry of this piece is shown in Figure 7.

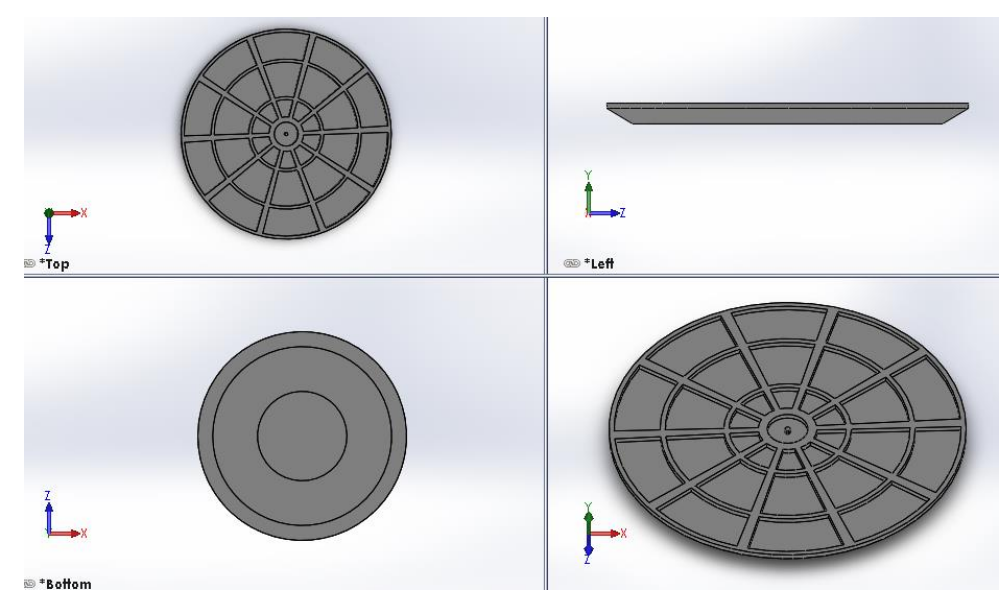




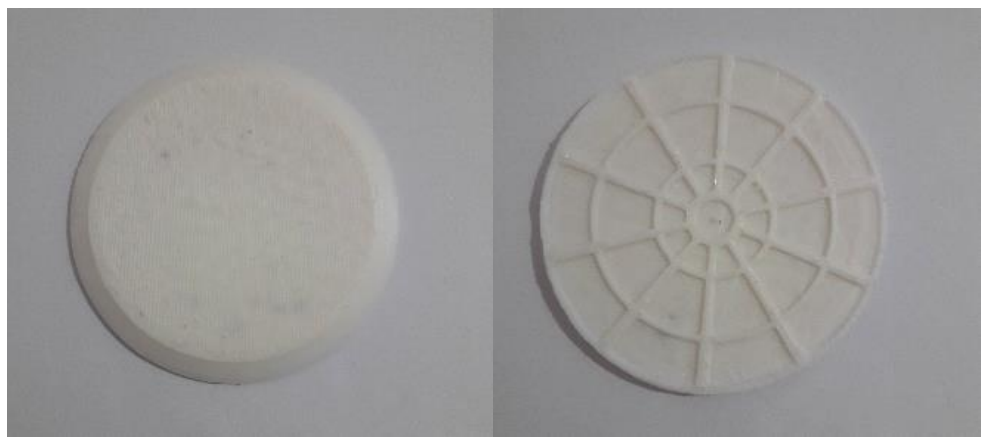

Figure 7. A plate of Teflon between the magnet and the body

By placing the designed piece, the pressure applied by the magnet is spread on the surface of the nose, so the stress can be neutralized in a larger radius. On the other hand, the most stress that is created at the surface of the nose is the flexural stress. Therefore, the presence of this piece as a support will decrease the amount of surface bending thus, reducing the stress due to water pressure. The linearity of the equation still exists, which simplifies estimating the required force. The linearity of the equations can be seen in Figure 8.

Figure 8 (a) shows a pressure of $9.81 * 10^{4} \mathrm{~Pa}$ (equivalent to $69.3 \mathrm{~N}$ ) and Figure 8 (b) shows a double pressure $\left(1.962 * 10^{5} \mathrm{~Pa}\right)$. It can be seen that the resulting stress has also doubled. The linearity of the system means that adding a Teflon disk acts like adding a load.

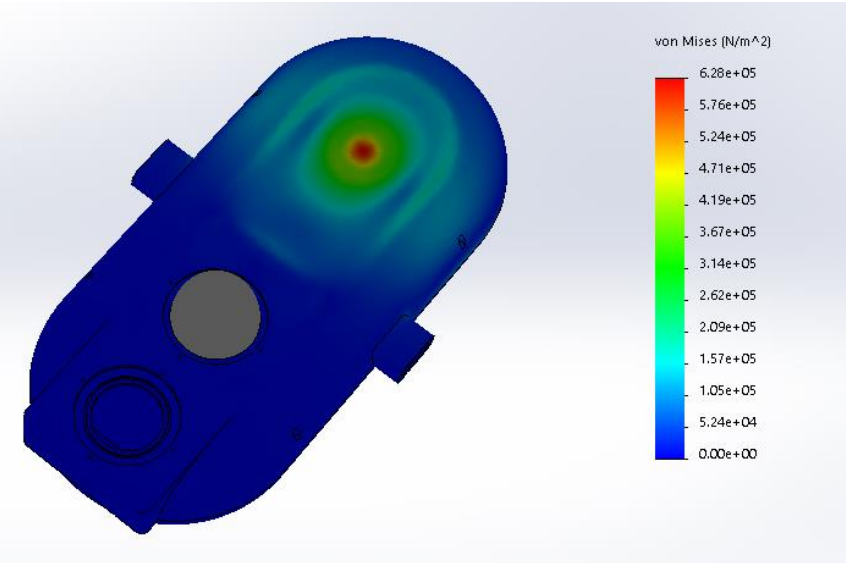

(a)

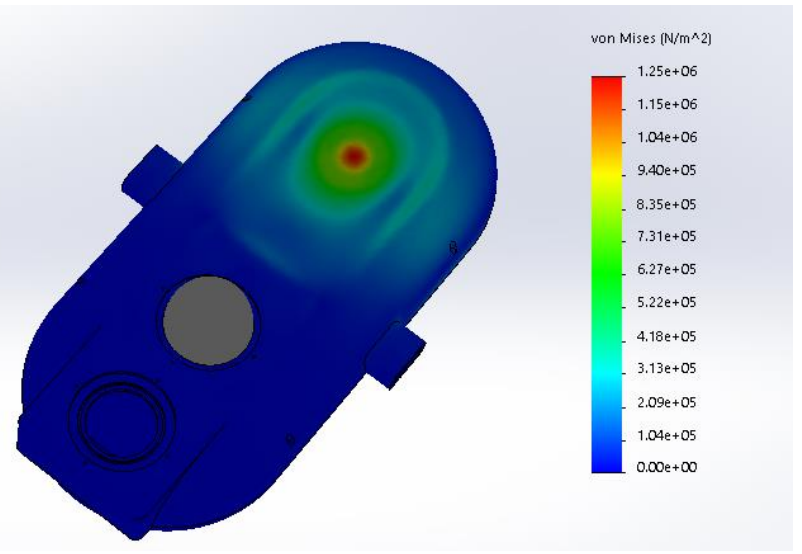

(b)

Figure 8. Pressure stress: (a) the maximum body stress is $6.28 * 10^{5} \mathrm{~Pa}$, and internal pressure is $9.81 * 10^{4} \mathrm{~Pa}$, (b) the maximum stress is $1.25 * 10^{6} \mathrm{~Pa}$ shows that doubling the internal pressure has caused a higher tension in the body 
According to Figure 9, the added piece neutralizes more surface stress of the nose. Two magnetic systems are used to cover the surface of the nose completely. In the final system, maximum stress is $7.45^{*} 10^{5}$ $\mathrm{Pa}$ if the internal pressure is $9.81 * 10^{4} \mathrm{~Pa}$ and the maximum stress is $8.5^{*} 10^{6} \mathrm{~Pa}$ on the nose surface under the external pressure of $9.8 * 10^{3} \mathrm{~Pa}$.

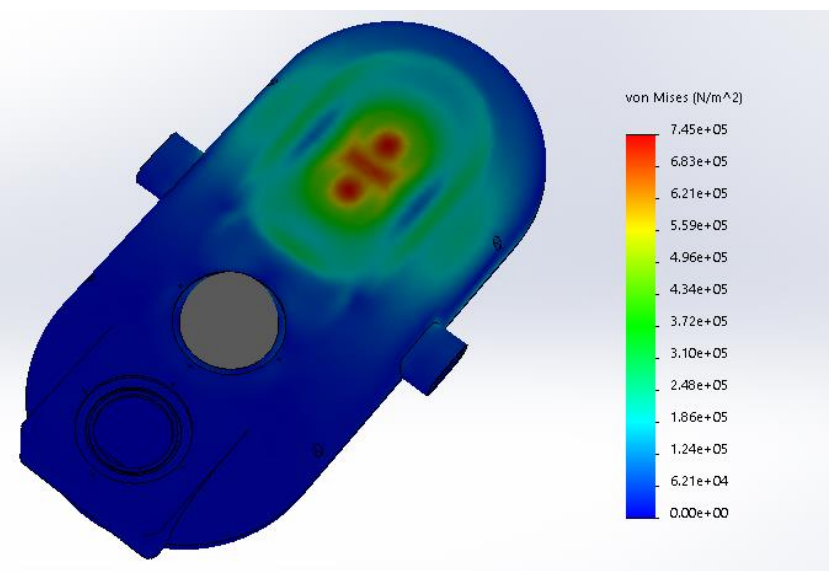

(a)

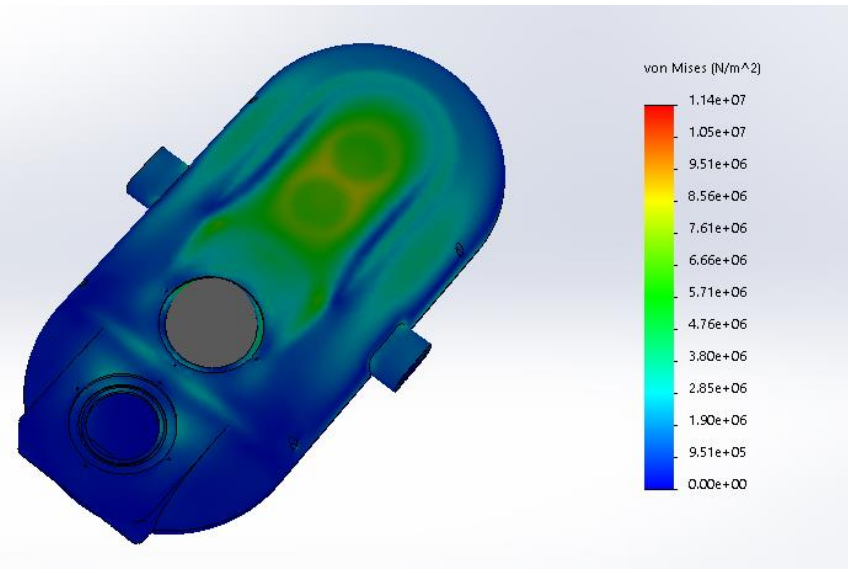

(b)

Figure 9. Using two magnetic systems to cover the entire surface of the nose: (a) internal pressure of $9.81 * 10^{4} \mathrm{~Pa}$, which creates a maximum stress of $7.45 * 10^{5} \mathrm{~Pa}$ on the nose, (b) External pressure of $9.81 * 10^{4}$ $\mathrm{Pa}$, which creates a maximum stress of $8.5^{*} 10^{6} \mathrm{~Pa}$ on the nose. The presence of the disk increases the effect of internal and external stress by 0.745 and 0.88 times respectively

Since the maximum allowable stress of PTFE is $6.57 * 10^{6} \mathrm{~Pa}$, and according to Figure 9 , the internal pressure should be 2.59 times greater than the external pressure to neutralize the stress of the body at a depth of 10 meters.

The amount of stress that must be neutralized to reach the allowable working depth of 10 meters $=$ $8.5 * 10^{6}-6.57 * 10^{6}=1.93 * 10^{6} \mathrm{~Pa}$.

$$
\begin{aligned}
& \frac{1.93 * 10^{6}}{7.45 * 10^{5}}=2.59 \\
& \text { If } \mathrm{P}_{2}=2.59 * 9.81 * 10^{4} \mathrm{pa}=2.54 * 10^{5} \mathrm{pa}
\end{aligned}
$$

So, $\mathrm{F}=\mathrm{P}_{2} *$ cross section of magnet $=\mathrm{P}_{2} * 0.03^{2 *} \pi / 4=179.5 \mathrm{~N}$

To create such a force, the following arrangement is shown in Figure 10. 


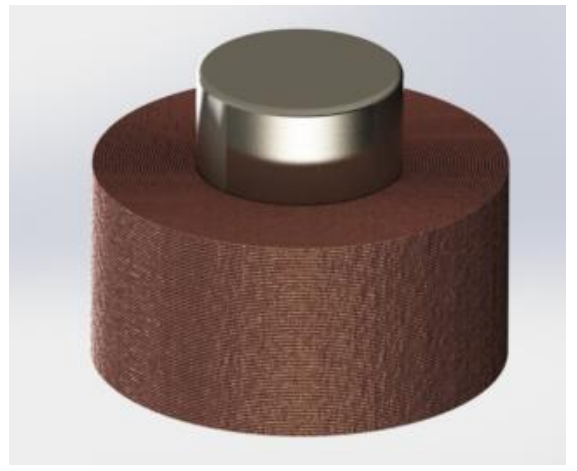

Figure 10. Magnet with a diameter of $3 \mathrm{~cm}$ and a height of $3 \mathrm{~cm}$, a coil with 1800 rounds of $0.5 \mathrm{~mm}$ wire, a height of $3 \mathrm{~cm}$ and a diameter of $6 \mathrm{~cm}$, the distance between the coil and the magnet is $1.5 \mathrm{~cm}$

To obtain a force of $179.5 \mathrm{~N}$ between the defined coil and magnet in Figure 10, a current of $6.06 \mathrm{~A}$ in the coil is then needed.

Obviously, as the AUV increases its depth, it becomes more stressed and consequently more stressed. If we want to neutralize the stress at different depths with a constant force, we will need to use the maximum current consumption of the magnetic system ( $6 \mathrm{~A}$ is equivalent to $180 \mathrm{~N}$ of force). For example, if the robot crosses the allowable depth of 6.5 meters, the magnetic system turns on and exerts $180 \mathrm{~N}$. Therefore, the stress on the body at a depth of 7 meters, which is slightly higher than the allowable depth of 6.5 meters is shown in Figure 11.

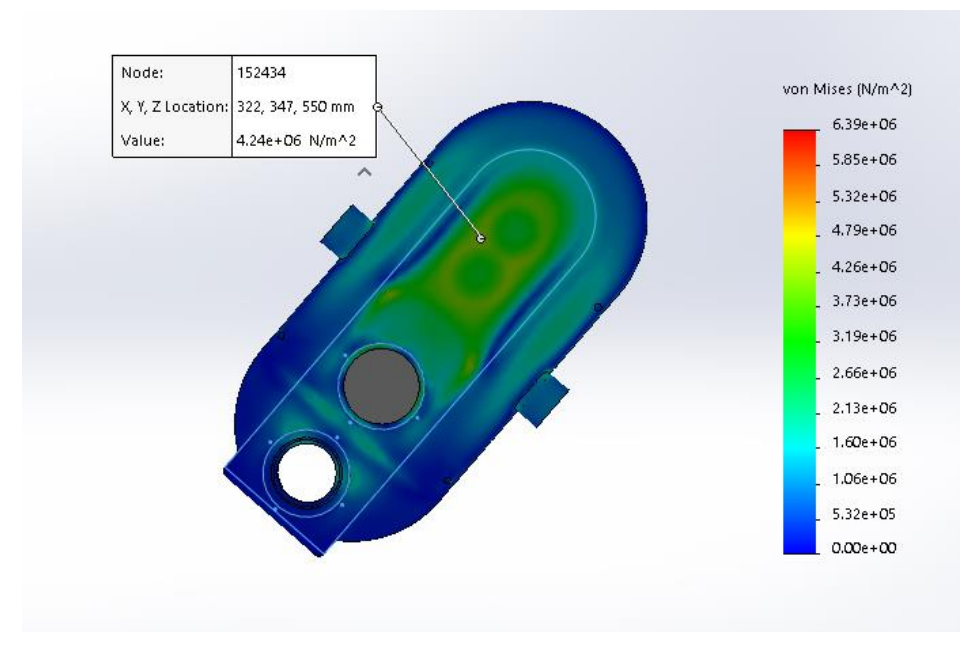

Figure 11. The tension on the body is 7 meters deep, and the internal force is $180 \mathrm{~N}$

As it shows, the maximum tension on the nose is $4.24 * 10^{6} \mathrm{~Pa}$, which means that more tension is neutralized and very low tension is applied to the body.

\section{FUZZY LOGIC CONTROL}

Mamdani fuzzy systems are primarily designed to mimic the performance of human operators responsible for controlling certain industrial processes [21], [22]. They are intended to summarize the operator experience in a set of IF-THEN rules used by a machine to control the system automatically. In a Mamdani fuzzy system, the function $\mathrm{f}$ is defined, which produces the numerical outputs $\mathrm{y}=\mathrm{f}(\mathrm{x})$ from the input values of $\mathrm{x}$. The general form of Mamdani fuzzy system is as "IF X is / is not A THEN Y is B". When the system has more than one input, the fuzzy rules take the form "IF X is A AND / OR Z is C THEN Y is B" [20]-[23]. 
To use a fuzzy control system, first the membership function of all inputs and outputs and the fuzzy rules of the system are defined. As shown in Figure 12, each input undergoes the following steps to create the desired output:

a. Fuzzification: According to the functions of the input members, the defined inputs, which may or may not be numbers, are converted to a set of input numbers of the fuzzy system with a min/max comparator.

b. Using the defined fuzzy rules, the set of input numbers of the system are converted to the set of output numbers of the fuzzy system.

c. The outputs of the system are defuzzified and the output of the intelligent system is calculated.

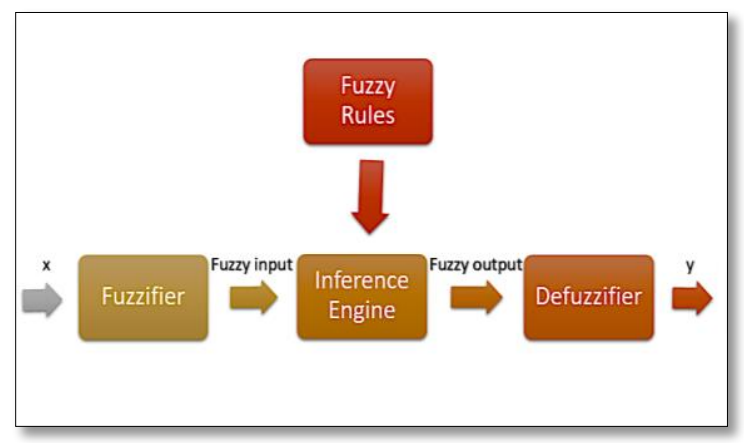

Figure 12. Block diagram of intelligent system control using fuzzy system

In this paper, increasing the vehicle depth is done with fixed steps of $0.5 \mathrm{~m}$. Therefore, the pressure applied to the body increases stepwise and there is no need for the maximum current of the coils at all defined depths. Thus, using the fuzzy controller system, the force is produced in proportion to the pressure on the body at any depth, which reduces the battery consumption and increases the operating time of the system. The input of this fuzzy system is the pressure measured by the pressure sensor and the output is the current required by the coil.

The robot's operating depth is set based on the pressure changes (that are directly related to the AUV's operating depth). According to the previous section, the allowable depth according to the structure and material of the AUV is 6.5 meters. In this section, the maximum working depth is raised to 10 meters. According to Figure 13, the AUV's operating depth from 6.5 meters to a depth of 10 meters is divided into half-meter zones to use this division in the fuzzy table. This division leads to 8 zones from a depth of up to $6.5,7,7.5,8,8.5,9,9.5$, and 10 meters. The reason for this division is to prevent a sudden increase in current in the system, reduce battery consumption, and increase its life.

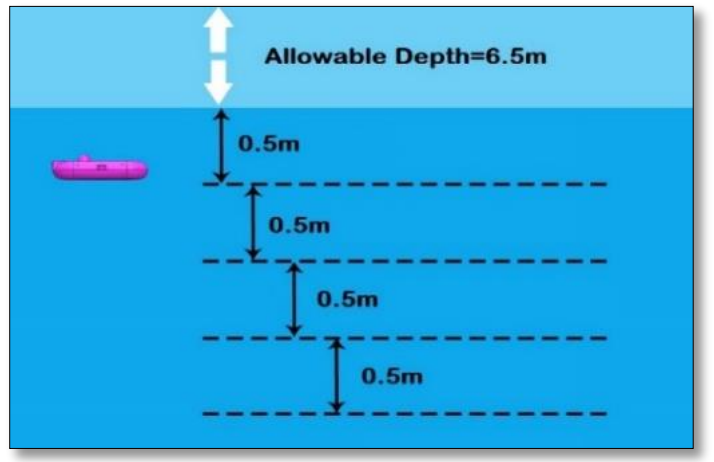

Figure 13. To divide the vehicle depth, every half meter is considered as a depth

For every half meter of increase in depth of water, the pressure increases by $4.9 * 10^{3} \mathrm{~Pa}$. As mentioned, the allowable stress of the PTFE body is $6.57 \mathrm{MPa}$, which is equivalent to a depth of 6.8 meters and a pressure of $6.67 * 10^{4} \mathrm{~Pa}$. Therefore, the body does not need a neutralizer to a depth of 6.5 meters and the magnetic system will be off. The MS5803-14BA sensor is used to measure the depth. For this reason, the fuzzy table is also written based on water pressure. The optimum depth is 6.5 meters. Thus, the suitable

Increasing the operating depth of an autonomous underwater vehicle using an intelligent ... (Ali Jebelli) 
pressure $\mathrm{P}_{\mathrm{s}}$ is $6.38^{*} 10^{4} \mathrm{~Pa}$. Error is the difference between the calculated pressure $\mathrm{P}_{\mathrm{c}}$ and the suitable pressure $\mathrm{P}_{\mathrm{s}}$. As the error increases, the vehicle is available in deeper areas. The error rate is the difference between the two final recorded errors. A positive error rate means that the vehicle is moving to a lower depth. Moreover, a negative error rate indicates that the vehicle is approaching the water surface.

$$
\mathrm{P}_{\mathrm{s}}=\text { suitable pressure }=6.38 * 10^{4} \mathrm{~N} / \mathrm{m}^{2}
$$

Error $=\mathrm{P}_{\mathrm{c}}-\mathrm{P}_{\mathrm{s}}$

Error rate $=$ error $(\mathrm{k})$-error $(\mathrm{k}-1)$

In this system, if the error is high, the input current will also be high, if the error is low, the input current will also be low, if the error is constant and the error rate is more positive, the input current should be higher and if the error is constant and the error rate is more negative, the input current will be lower, see in Figures 14-16. Tables 2-5 show error levels, error rate levels, Output levels (I), size, and Fuzzy rules.

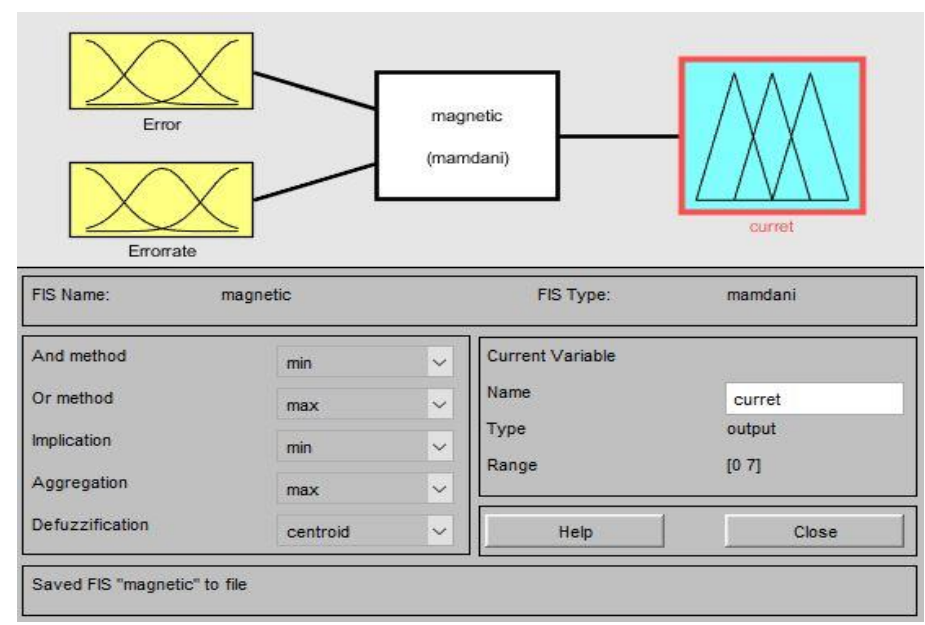

Figure 14. Defined Mamdani fuzzy system

In this system, and is equal to min and or is equal to max. Error and Error rate are system inputs and output current

Table 2. Determining error levels

\begin{tabular}{ccccccccc}
\hline Error level & ZR & VVS & VS & S & M & B & VB & VVB \\
\hline Error $(\mathrm{P})$ & 0 & $4.9 * 10^{3}$ & $9.8 * 10^{3}$ & $1.47 * 10^{4}$ & $1.96 * 10^{4}$ & $2.45 * 10^{4}$ & $2.94 * 10^{4}$ & $3.43 * 10^{4}$ \\
\hline
\end{tabular}

Table 3. Determining error rate levels

\begin{tabular}{cccccccc}
\hline Error rate levels & $\mathrm{NB}$ & $\mathrm{NM}$ & $\mathrm{NS}$ & $\mathrm{ZR}$ & $\mathrm{PS}$ & $\mathrm{PM}$ & $\mathrm{PB}$ \\
\hline Error rate & $-10^{4}$ & $-5 * 10^{3}$ & $-2.5^{*} 10^{3}$ & 0 & $2.5 * 10^{3}$ & $5^{*} 10^{3}$ & $10^{4}$ \\
\hline
\end{tabular}

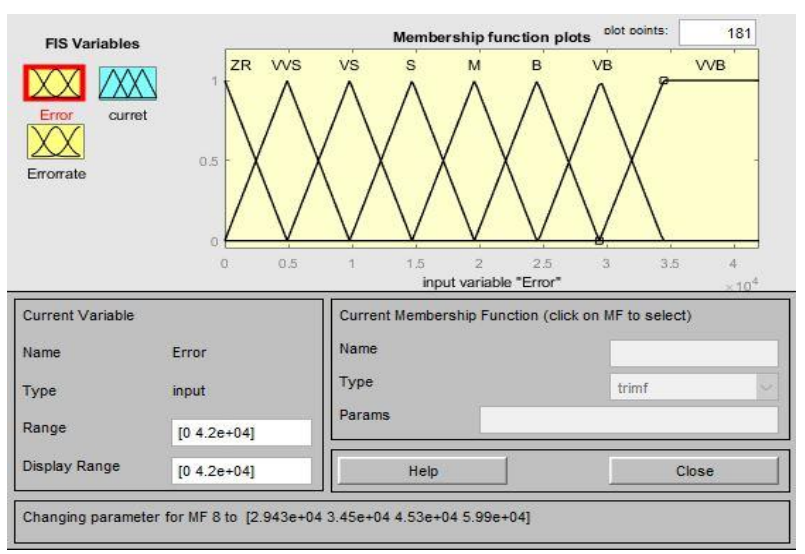

(a) 


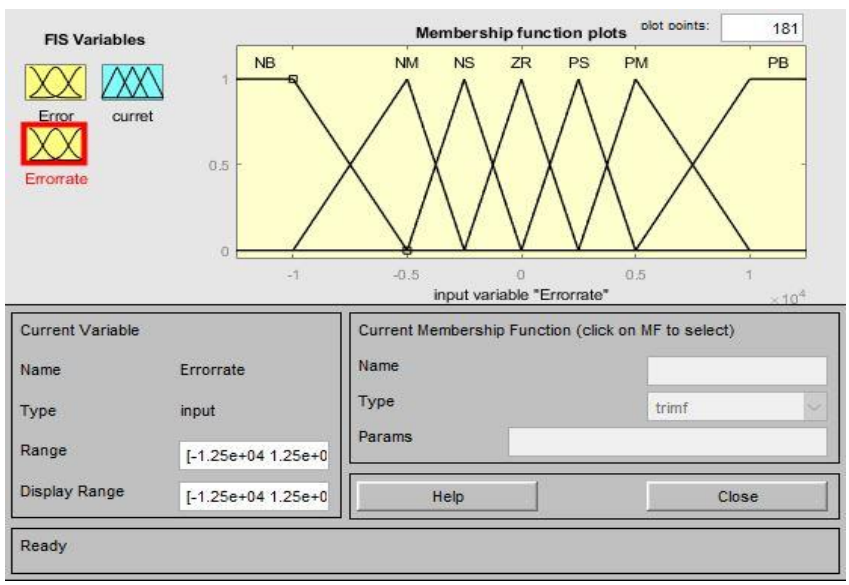

(b)

Figure 15. Membership functions: (a) Input error's membership functions, (b) Error rate membership functions

Table 4. Output levels: the output of the fuzzy system is current

\begin{tabular}{ccccccccc}
\hline Output levels & VVL & VL & L & M & F & VF & VVF & VVVF \\
\hline I & 0 & 0.87 & 1.75 & 2.63 & 3.5 & 4.37 & 5.25 & 6 \\
\hline
\end{tabular}

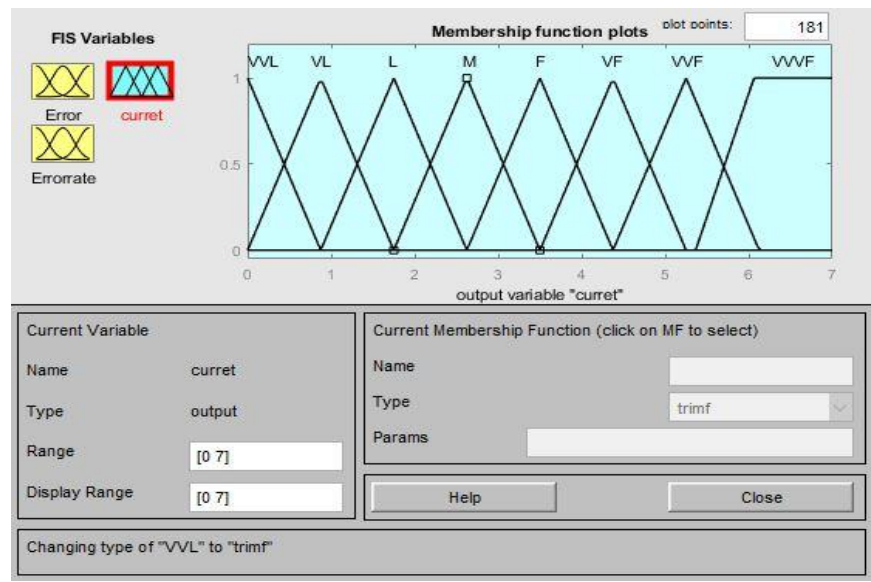

(a)

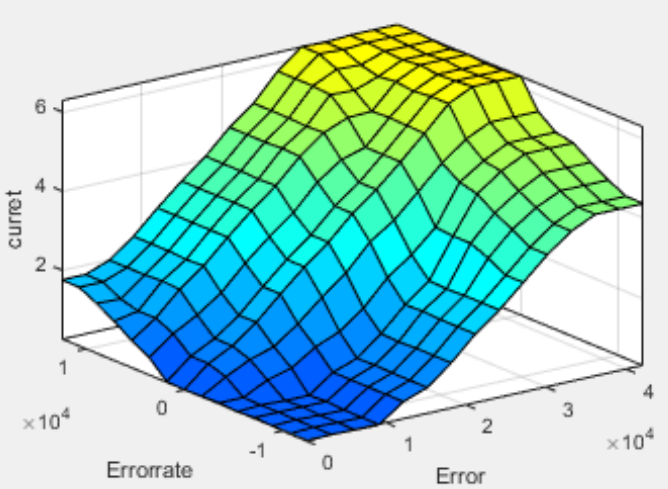

(b)

Figure 16. These figures are; (a) Output error's membership functions, (b) Diagram of the designed fuzzy system 
Table 5. Fuzzy rules table

\begin{tabular}{ccccccccc}
\hline E & ZR & VVS & VS & S & M & B & VB & VVB \\
\hline NB & VVL & VVL & VVL & VL & L & M & F & VF \\
NM & VVL & VVL & VVL & VL & L & M & VF & VVF \\
NS & VVL & VVL & VL & L & M & F & VF & VVF \\
ZR & VVL & VL & L & M & F & VF & VVF & VVVF \\
PS & VVL & VL & L & M & F & VF & VVF & VVVF \\
PM & VL & L & M & F & VF & VVF & VVF & VVVF \\
PB & L & L & M & F & VF & VVF & VVVF & VVVF \\
\hline
\end{tabular}

\section{TESTS}

\subsection{Test 1}

In this test, the body is exposed to $9.43^{*} 10^{4} \mathrm{~Pa}$. This pressure is equivalent to a depth of 9.6 meters. According to the fuzzy system, 5.52 A must be applied to the system to have the body stress in the allowable load range, see in Figure 17 and Figure 18.

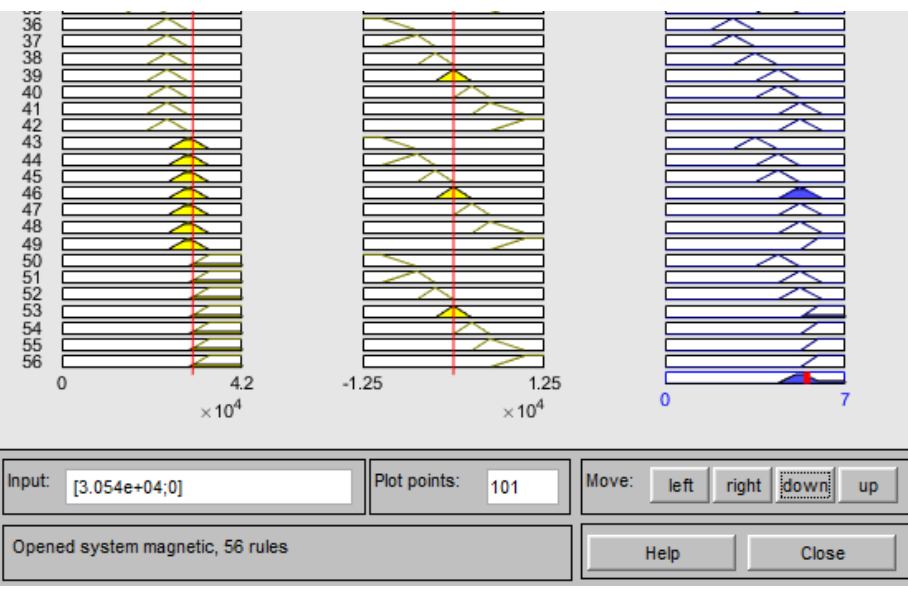

Figure 17. Example of a fuzzy system

According to Figure 17, here the error is $3.05^{*} 10^{4} \mathrm{~Pa}$ and the error rate is zero. The output current is measured as $5.52 \mathrm{~A}$.

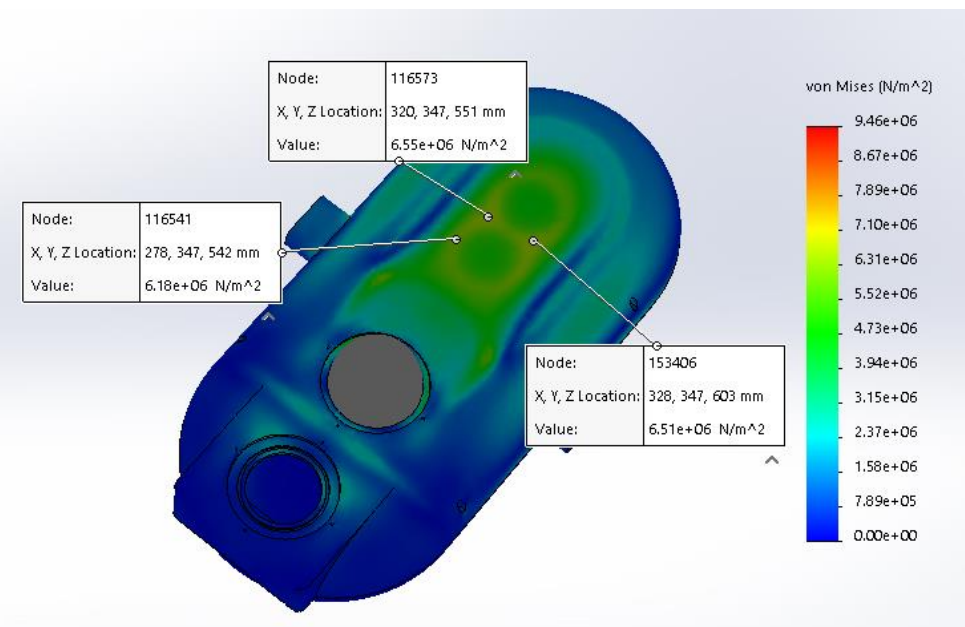

Figure 18. Neutralizing the external pressure of $9.43 * 10^{4} \mathrm{~Pa}$ with two coils of $5.52 \mathrm{~A}$ 


\subsection{Test 2}

In this test, see in Figure 19 and Figure 20, the body is exposed to $8 * 10^{4} \mathrm{~Pa}$. This pressure is equivalent to a depth of 8.1 meters. According to the fuzzy system, 2.92 A must be applied to the system to have the body stress in the allowable load range.

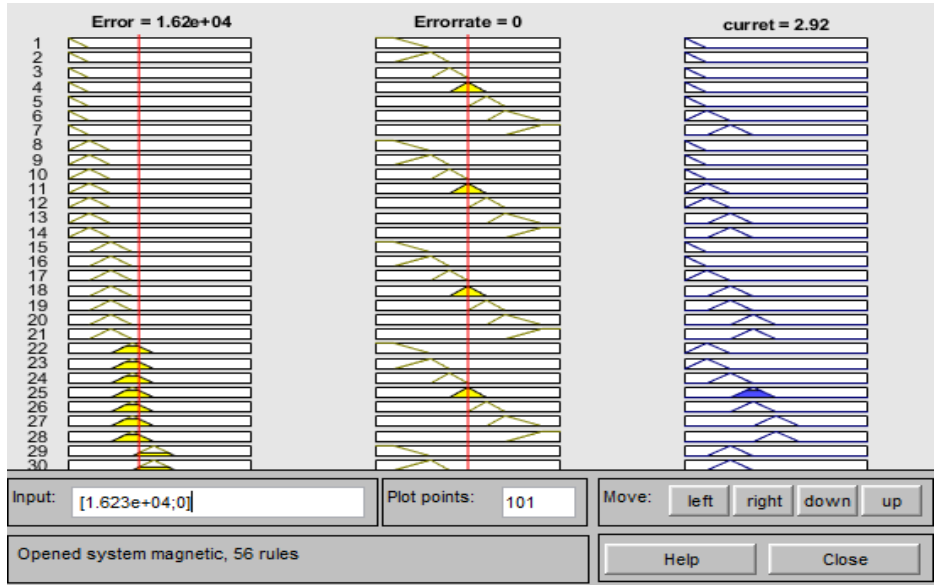

Figure 19. Example of a fuzzy system

According to Figure 17, here the error is $1.62 * 10^{4} \mathrm{~Pa}$ and the error rate is zero. The output current is measured as $2.92 \mathrm{~A}$.

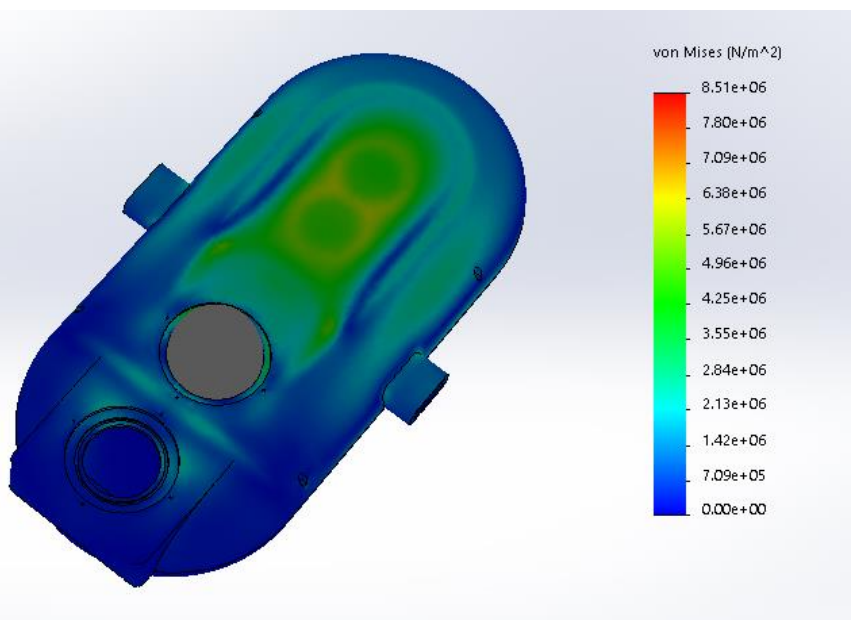

Figure 20. Neutralizing the external pressure of $8 * 10^{4} \mathrm{~Pa}$ with two coils of $2.92 \mathrm{~A}$

\section{CONCLUSION}

The increasing applications of the underwater AUVs in underwater research and studies have attracted the attention of many researchers. One of the biggest challenges of these AUVs is having a body with very high mechanical strength and at the same time small, very light, and with enough space. A suitable body has a huge influence on factors such as depth rating, motion control, system's hydrodynamic, localization, cost, deploying tools, and sensors. As the depth of the sea increases, the parameters of the environment, including pressure, $\mathrm{pH}$, and temperature also change, which lead to deformation of the body, changes in the hydrodynamics of the system, and sometimes body failure and drowning of the AUV. In this paper, the AUV's working depth without changing the shape of the body and AUV equipment is increased to an acceptable level by placing a small, low-error magnetic system at the maximum stress point on the AUV, which is located on its nose and is previously determined by software in real conditions. In this system, the working depth of the AUV is increased by more than $50 \%$ by the magnetic repulsion force by a coil with a magnet core. This force is dispersed by a thin and very light disk on the surface of the AUV nose to cover a larger area. In this article, the software analyses of the body stress are performed to show the effect of 
magnetic force, then using MATLAB, the required specifications of the required coil are estimated and the fuzzy system is implemented. This study showed that this system is able to compensate for the pressure on the AUV body measured by the sensor at different depths; the fuzzy controller in this system increases the optimal battery consumption and operating time of the system. This system is small and low cost and can be used in underwater AUVs of different sizes without changing the system structure.

\section{REFERENCES}

[1] J. W Nicholson and A. J. Healey, "The present state of autonomous underwater vehicle (AUV) applications and technologies," Marine Technology Society Journal, vol. 42, no. 1, pp. 44-51, 2008, doi: 10.4031/002533208786861272.

[2] Y. Shi, G. Pan, S. C. Yim, G. Yan, D. Zhang. "Numerical investigation of hydroelastic water-entry impact dynamics of AUVs," Journal of Fluids and Structures, vol. 91, pp. 102760, 2019, doi: 10.1016/j.jfluidstructs.2019.102760.

[3] W Gan, D. Zhu, and S. X. Yang, "A Speed Jumping-Free Tracking Controller with Trajectory Planner for Unmanned Underwater Vehicle.," International Journal of Robotics and Automation, vol. 35, no. 5, 2020, doi: 10.2316/J.2020.206-0309.

[4] A. S. Arockia, D. Venkatesh, and M. Ovinis, "Simulation And Experimental Studies of a Mobile Robot for Underwater Applications," International Journal of Robotics and Automation, vol. 35, 2020, doi: 10.2316/J.2021.206-0424.

[5] Z. Cui and H. Jiang, "Complex Modal Analysis of Locomotive Motions of Soft Robotic Fish," International Journal of Robotics and Automation, vol. 35, 2020, doi: 10.2316/J.2021.206-0355.

[6] A.Jebelli, C. E. Yagoub, and S. B. Dhillon, " Using a High-Speed Mini-PC to Control an Autonomous Underwater Vehicle," American Journal of Mechanical Engineering, vol. 7, no. 3, pp. 116-128, 2019, doi: https://doi.org/10.12691/AJME-7-3-2.

[7] A Jebelli, "Design of an Autonomous Underwater Vehicle with Vision Capabilities," Ph.D. thesis, University of Ottawa, Ottawa, 2016, doi: 10.20381/ruor-316.

[8] A. Jebelli., C. E. Yagoub, and S. B. Dhillon, "Intelligent Control System for Autonomous Underwater Robots with Vision Capabilities," Journal of Applied Mechanical Engineering, vol. 6, no. 3, pp. 1-7, 2017, doi: 10.4172/21689873.1000270

[9] Y. L. Diao, W. N.Sun, Y. Q. He, S. W. Leung, and Y. M. Siu, "Equivalent magnetic vector potential model for low-frequency magnetic exposure assessment," Physics in Medicine \& Biology, vol. 62, no. 19, pp. 7905, 2017.

[10] A.Jebelli, A. Mahabadi, M. C. E. Yagoub, H. Chaoui, "Magnetic Force Calculation between Magnets and Coils," International Journal of Physics, vol. 8, no. 2, pp. 71-80, 2020, doi: 10.12691/ijp-8-2-5.

[11] S. McPhail, "Autosub6000: A deep diving long range AUV," Journal of Bionic Engineering, vol. 6, no. 1, pp. 5562, 2009 doi: 10.1016/S1672-6529(08)60095-5.

[12] Woolfrey, Jon, W. Lu, T. V. Calleja, D. Liu, "Clarifying clairvoyance: Analysis of forecasting models for nearsinusoidal periodic motion as applied to AUVs in shallow bathymetry," Ocean Engineering, vol. 190, pp. 106385, 2019, doi: 10.1016/j.oceaneng.2019.106385.

[13] A. A. Yusof, M. K. M. Nor, S. A. Shamsudin, M. R. Alkahari, M. Musa, "The development of PANTHER AUV for Autonomous Underwater vehicle competition challenge 2017/2018," Intelligent Manufacturing \& Mechatronics, Springer, Singapore, pp. 259-269, 2018.

[14] K. D. Kaya, A. Goren, S. Yilmaz, K. Bayramoğlu, "Determination of operating parameters of an AUV following a preplanned trajectory using hydrodynamic analysis data," Ocean Engineering vol. 217, pp. 107708, 2020, doi: 10.1016/j.oceaneng.2020.107708.

[15] A. Jebelli, H. Chaoui, A. Mahabadi, B. S. Dhillon. "Tracking and mapping system for an underwater vehicle in real position using sonar system," International Journal of Robotics and Automation - ACTA Press, vol. 36, 2021.

[16] I. R. Ciric, "New models for current distributions and scalar potential formulations of magnetic field problems," Applied Physics, vol. 61, pp. 2709, 1987, doi: doi.org/10.1063/1.337911.

[17] W. Robertson, B. Cazzolato and A. Zander, "Axial Force Between a Thick Coil and a Cylindrical Permanent Magnet: Optimizing the Geometry of an Electromagnetic Actuator," in IEEE Transactions on Magnetics, vol. 48, no. 9, pp. 2479-2487, Sept. 2012, doi: 10.1109/TMAG.2012.2194789.

[18] F. Irgens, Continuum Mechanics, Springer, 2008.

[19] S. Timoshenko and S. Woinowsky-Krieger, Theory of plates and shells, McGraw-Hill New York, 1959.

[20] A. Jebelli, C. Yagoub \& S. Dhillon, "Design and Implementation of an Autonomous Underwater Vehicle (AUV) with PTFE," Advances in Robotics \& Automation, vol. 7, 2018, doi: 10.4172/2168-9695.1000185.

[21] S. Izquierdo, and L. R. Izquierdo, "Mamdani fuzzy systems for modelling and simulation: A critical assessment," Journal of Artificial Societies and Social Simulation, vol. 21, no. 3, 2016, doi: 10.2139/ssrn.2900827.

[22] M. Irfan, C. N. Alam, D. Tresna,"Implementation of Fuzzy Mamdani Logic Method for Student Drop Out Status Analytics," The 1st Workshop on Environmental Science, Society, and Technology, Journal of Physics, 2019, doi: 10.1088/1742-6596/1363/1/012056.

[23] I. Sakti, "Methodology of fuzzy logic with mamdani fuzzy models applied to the microcontroller," 2014 The 1st International Conference on Information Technology, Computer, and Electrical Engineering, 2014, pp. 93-98, doi: 10.1109/ICITACEE.2014.7065721. 


\section{BIOGRAPHIES OF AUTHORS}
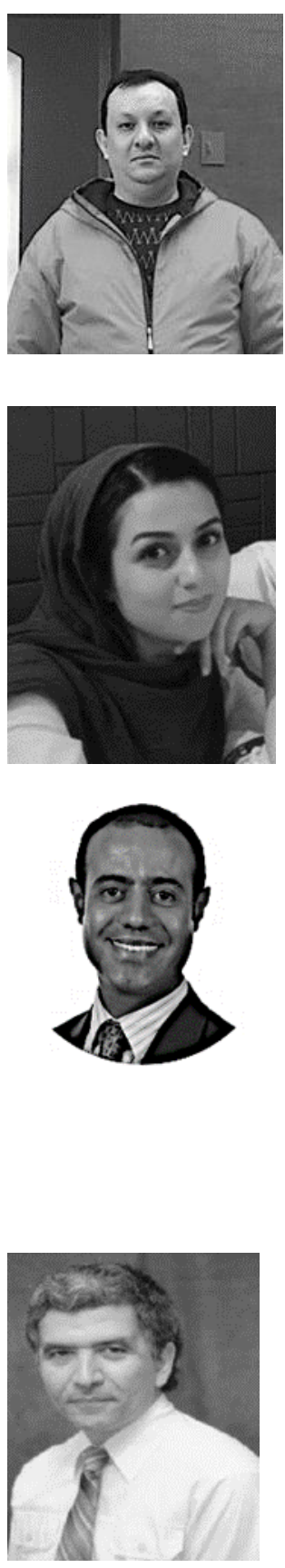

Ali Jebelli, received his Master's degree and Ph.D. in Electrical and Computer Engineering from the University of Ottawa in 2014 and 2016. During his studies at the University of Ottawa, he worked as a research assistant and teacher assistant in the Department of Mechanical Engineering and the School of Electrical Engineering and Computer Science, and during that time, he won several prestigious awards. He also received a Master degree (MEng) in ElectricalMechatronics and Automatic Control from the University Technology Malaysia in 2009, and his bachelor's degree in Electrical Power Engineering in 2005. His research interests include autonomous systems, intelligent control, robotics, mechatronics, electric motors drives, solar and wind energy. He has authored or coauthored over 80 publications in these topics in international journals and referred conferences. He currently holds a Post-Doctoral position in the Department of Mechanical Engineering at the University of Alberta.

Arezoo Mahabadi, is currently a graduate student in Shahed University. Arezoo received her B.Eng. degree with Honors in Basic Engineering Science from the University of Tehran in 2019. Her research interests include intelligent systems, robotics, mechatronics, mathematical modeling of stationary field, computational electromagnetics solar energy systems, sonar and radar systems, electric motor drives, and energy storage and management. She is currently supervisor of the engineering department at RoboticC Inc.

Hicham Chaoui, received the B.Sc. degree in electrical engineering from the Institut supérieur du Génie Appliqué (IGA), Casablanca, Morocco, in 1999, the M.A.Sc. degree in electrical engineering, the M.Sc. degree in computer science (with honors), the graduate degree in project management, and the Ph.D. degree in electrical engineering (with honors) all from the University of Quebec, Canada, in 2003, 2005, 2007, and 2012, respectively. His career has spanned both academia and industry in the field of intelligent control and renewable energies. Prior to his academic career, he held various engineering and management positions including VicePresident of Innovation and Technology Development. From 2014 to 2016, he was an Assistant Professor at Tennessee Technological University, TN, USA. He is currently a Faculty Member at Carleton University, Ottawa, ON, Canada and an Associated Faculty Member at the University of Quebec, Trois-Rivières, QC, Canada. His research interests include adaptive and nonlinear control theory, intelligent control, robotics, mechatronics, electric motor drives, and energy storage and management. He is a senior member of IEEE.

Mustapha C. E. Yagoub received the Dipl.-Ing. degree in Electronics and the Magister degree in Telecommunications, both from the École Nationale Polytechnique, Algiers, Algeria, in 1979 and 1987, respectively, and the Ph.D. degree from the Institut National Polytechnique, Toulouse, France, in 1994. After few years working in industry as a design engineer, he joined the Institute of Electronics, Université des Sciences et de la Technologie Houari Boumédiene, Algiers, Algeria, first as an Lecturer during 1983-1991 and then as an Assistant Professor during 19941999. From 1996 to 1999, he has been head of the communication department. From 1999 to 2001, he was a visiting scholar with the Department of Electronics, Carleton University, Ottawa, ON, Canada, working on neural networks applications in microwave areas. In 2001, he joined the School of Information Technology and Engineering (SITE), University of Ottawa, Ottawa, ON, Canada, where he is currently a Professor. His research interests include RF/microwave CAD, RFID design, neural networks for high frequency applications, planar antennas, and applied electromagnetics. He has authored or coauthored over 300 publications in these topics in international journals and referred conferences. Dr. Yagoub is an Editorial Board member of the International Journal of RF and Microwave Computer-Aided Engineering, a senior member of the IEEE, and a registered member of the Professional Engineers of Ontario, Canada. 